NBER WORKING PAPER SERIES

\title{
THE EFFECT OF SOFT BUDGET CONSTRAINTS ON ACCESS AND QUALITY IN HOSPITAL CARE
}

\author{
Yu-Chu Shen \\ Karen Eggleston \\ Working Paper 14256 \\ http://www.nber.org/papers/w14256
}

\author{
NATIONAL BUREAU OF ECONOMIC RESEARCH \\ 1050 Massachusetts Avenue \\ Cambridge, MA 02138
}

August 2008

We would like to thank Jonathan Skinner of Dartmouth College for providing us with the AMI hospitallevel mortality rates data; participants at Stanford RIP seminar for helpful comments on the earlier draft. Shen acknowledges financial support from the Naval Postgraduate School DFR program. The views expressed herein are those of the author(s) and do not necessarily reflect the views of the National Bureau of Economic Research.

NBER working papers are circulated for discussion and comment purposes. They have not been peerreviewed or been subject to the review by the NBER Board of Directors that accompanies official NBER publications.

(C) 2008 by Yu-Chu Shen and Karen Eggleston. All rights reserved. Short sections of text, not to exceed two paragraphs, may be quoted without explicit permission provided that full credit, including $\odot$ notice, is given to the source. 
The Effect of Soft Budget Constraints on Access and Quality in Hospital Care

Yu-Chu Shen and Karen Eggleston

NBER Working Paper No. 14256

August 2008

JEL No. I11,I18

\begin{abstract}
$\underline{\text { ABSTRACT }}$
Given an increasingly complex web of financial pressures on providers, studies have examined how the hospitals' overall financial health affect different aspects of hospital operation. In our study, we analyze this issue focusing on hospital access and quality by introducing an important aspect of the financial incentives, soft budget constraints (SBC), that takes into account both hospital's current and past financial health as well as their expected financial outlook (i.e., whether there is a sponsoring organization to bail them out). We develop a conceptual framework of SBC by considering the resultant incentives on cost control and quality improvement innovations; and examine the effect of SBC on the following aspects of access and quality: safety net service survival and AMI mortality rates. We find that hospitals with softer budget constraints are less likely to shut down safety net services. In addition, hospitals with softer budget constraints appear to have better mortality outcomes, suggesting that the reduced incentive to engage in cost control innovation as the result of SBC outweighs the dampening effect of quality improvement innovation.
\end{abstract}

Yu-Chu Shen

Graduate School of Business and Public Policy

Naval Postgraduate School

555 Dyer Road

Monterey, CA 93943

and NBER

yshen@nps.edu

Karen Eggleston

Stanford University

Shorenstein Asia-Pacific Research Center

Encina Hall E301

Stanford, CA 94305-6055

karene@stanford.edu 


\section{Introduction}

Over the past several decades, the US healthcare system has undergone significant structural changes and payment system reforms, creating an increasingly complex web of financial pressures on providers. These financial pressures have resulted in shrinking hospital margins in the past decade: the percent of general acute hospitals reporting negative income grew from 21 percent in 1995 to 29 percent in 2004, ${ }^{1}$ and Medicare margins fell by 50 percent between 1997 and 2001 (MedPAC, 2005). The shrinking margins have prompted concerns about financial stress leading to worse access and quality of care for patients.

An extensive literature focuses on how financial stress affects hospital operations, including several studies that have examined how hospitals' past and current profit margins affect quality of care as measured by safety events and mortality (Encinosa and Bernard, 2005; Bazzoli et al 2007). While current and past financial circumstances can be important, they do not fully capture future financial health, such as whether the hospital can expect to be bailed out from future troubles. Yet it is the expectation of future circumstances and the present value of those future revenue streams that shape key current choices about operations.

In this study, we propose another way to understand how a hospital's financial health can affect access and quality in patient care by introducing the concept of a soft budget constraint $(\mathrm{SBC})$, which takes into account potential future profit by considering whether the hospital will be bailed out by a sponsoring organization (such as government). Both theory and empirical evidence suggest that SBCs often play an important role in explaining organizational behavior (Kornai, Maskin, and Roland 2003), including differences among otherwise similar organizations. Yet few researchers have referenced this theory to help understand the "black box" of healthcare organization decision making.

The objective of this paper is twofold: (1) to develop a conceptual framework and empir-

\footnotetext{
${ }^{1}$ Authors' tabulation of Medicare hospital cost reports (HCRIS).
} 
ical metrics of soft budget constraints for the US hospital industry; and (2) to analyze the effect of soft budget constraints on hospital access and quality. For access measures, we examine the survival rates of safety net services, including inpatient and outpatient substance abuse services, HIV/AIDS services, and emergency departments. For quality measures, we examine time-specific risk adjusted mortality rates among Medicare AMI patients. We specifically examine the following hypotheses derived from our conceptual framework:

1. Hospitals with harder budget constraints have a higher risk of shutting down safety net services.

2. If important aspects of hospital quality are noncontractible and potentially damaged by cost control, then softer budget constraints will be associated with higher quality (lower AMI mortality rates).

Our primary data sources are the American Hospital Association annual surveys and hospital cost reports from the Centers for Medicare and Medicaid Services, as well as Medicare fee-for-service claims for AMI outcomes. Our sample includes all general, acute, short-stay hospitals between 1990 and 2004. The rest of the paper proceeds as follows. We review the literature pertaining to the relationship between hospital financial health and access and quality in section 2. We present the conceptual framework of SBCs and the theoretical predictions regarding the effect of SBCs on access and quality in section 3. We describe the data and the empirical models in section 4. We present the empirical results in section 5 and conclude in section 6 .

\section{Background Literature}

Most studies analyzing the relationship between financial pressure and hospital behavior use changes in insurer markets, mostly Medicare payment policy, as a measure of financial pressure. In general, the literature has found a significant negative effect of payment cuts on patient outcomes in the earlier period when Medicare transitioned from cost reimbursement 
to the Prospective Payment System (Staiger and Gaumer 1992; Cutler 1995; Shen 2003), but only a small to nonexistent effect on patient outcomes when Medicare imposed uniform rate cuts across hospitals in the 1997 Balanced Budget Act (Volpp et al 2005; Clement et al 2007; Lindrooth et al 2007). Financial pressure from managed care has also been studied extensively, with mixed results regarding its effect on patient care (see Morrisey 2001 for a review). A few studies directly examine a hospital's own financial health and its impact on patient safety. Encinosa and Bernard (2005), using HCUP data from Florida hospitals between 1996 and 2000, found that a lower operating margin was associated with increased odds of adverse patient safety events. Bazzoli et al (2007), using HCUP data from 11 states between 1994 and 2000, found a weaker relationship between profit margin and quality of care, but noted that hospitals in the lowest 2 quartiles of the cashflow-to-total revenue ratio have worse outcomes for some but not all quality indicators.

Whether researchers use external financial pressure from insurer markets or a hospital's internal financial health as the key independent variable, the common theme in this literature has been the focus on current or past financial information. However, many key current choices about hospital operations (such as provision of safety net services or implementation of innovations) are shaped by the expectation of future circumstances and the present value of those future revenue streams, which may not be fully revealed in past profit margins. Our study considers an alternative financial measure to examine these important access and quality issues. We introduce the concept of soft budget constraints and discuss studies that have directly or indirectly incorporated SBCs in assessing hospital behavior. We will develop the SBC concept more fully in the next section.

An organization enjoys a SBC if it can expect to continue to operate when expenditures consistently exceed revenues, because some sponsoring organization, such as the government or the parent company, provides funds to prevent going out of business (Kornai 1986). Organizations expecting bail-outs have less incentive to be efficient and strive for innovation, although their resilience in the face of financial difficulty also may help to guarantee supply 
of a valuable service. Organizations enjoying SBCs also often suffer from a 'ratchet effect': in good times, their surpluses are diverted or expropriated for other uses by the sponsoring organizations.

Some previous researchers have shown that expropriation affects hospital behavior (e.g., Duggan 2000), although none have studied the direct SBC effect on service provision and patient outcomes. Baicker and Staiger (2005) show that a significant share of federal funds intended to supplement resources for safety-net hospitals was actually appropriated by state and local governments for other uses. The Disproportionate Share (DSH) funds that were put to their intended use, rather than diverted, did help to improve population health (through reductions in infant and post-heart attack mortality). Duggan (2000) shows that in California, local governments decreased their subsidies to government-owned hospitals almost dollar-for-dollar with the increased state revenues those hospitals received from the DSH program. In light of this expropriation, California government hospitals saw no change in total revenues, despite continuing to treat the least profitable patients.

These studies are suggestive that SBCs and expropriation of financial surplus are indeed important phenomena affecting hospitals. However, no study that we are aware of explicitly examines the relationship between a metric for SBC and hospitals' service offerings and quality of care, although theory suggests that these are aspects of hospital operations that may be significantly shaped by the softness of a hospital's budget constraint.

\section{Conceptual Framework}

In this section, we lay out the framework that explains how the SBC concept takes into account a hospital's expectation of its future financial circumstances and the likely effect of this expectation on hospital access and quality. Our simple model builds on the model of noncontractible innovations in Hart, Shleifer and Vishny (1997; hereafter HSV) and model of SBCs in Eggleston (2008). Our contribution is to re-frame these elements to derive empiri- 
cally testable hypotheses about how softness of budget constraints influences cost control and quality of services, abstracting from (and empirically controlling for) other aspects shaping hospital behavior such as ownership. We first introduce the players and the decision stages, and discuss the key components of the theoretical model. We then proceed to define SBCs formally, and present theoretical predictions of how SBCs shape innovation incentives. It is these theoretical predictions that we test empirically in the remainder of the paper.

\subsection{Players and timeline}

At Date 0, the manager, M, of a health service facility such as a hospital agrees to provide payer(s) a basic package of health services of quality $B_{0}$ for payment $P_{0}$. The services cost the manager $C_{0}$ to provide. At Date 0.5, M develops ideas (blueprints) to control costs, $e$, and to improve quality, $i$. These changes in service offerings or care processes were neither proscribed nor required in the initial contract; they were either technically noncontractible ex ante (at date 0 ) or not considered important or cost-effective to stipulate explicitly. For example, hospitals frequently are included in insurer networks without a specific contract that requires provision of a long list of safety net services or specific threshold of care quality. Likewise, although city or county hospitals have an obligation to provide indigent care, the specifics of the services are not written in contracts. ${ }^{2}$ Stipulating exact care processes, staffing expectations, and other details of hospital management are neither practical nor common. Thus hospital managers have considerable scope for changing operations to improve quality and/or reduce cost.

At Date 1, M and the owner(s) and payer(s) renegotiate over the proposed changes (innovation blueprints), agreeing to split the associated surplus $S(e, i)$ according to bargaining power and market conditions: the owner(s) and payer(s) appropriate fraction $(1-m)$ of the surplus $(0 \leq m \leq 1)$, and $\mathrm{M}$ retains $m S$. At Date 1.5, $\mathrm{M}$ chooses implementation effort that determines the probability that innovations $e$ and $i$ are successfully implemented. At

\footnotetext{
${ }^{2}$ Communication with Gene Marie O'Connell, CEO of San Fransicsco General Hospital.
} 
Date 2, the payer(s) and owners assess the performance of the manager and current market conditions, and decide whether or not to close the facility (e.g. hospital) that M manages. If the innovations have not been implemented successfully, the facility may continue to provide the basic service - yielding positive benefits $V_{o}$ to the payer(s)/owner(s) and $U_{o}$ to $\mathrm{M}-$ or be closed. In the event of closure, $\mathrm{M}$ experiences a loss of $U_{L}<0$ (representing reputation losses and costs associated with finding a new job). We summarize the flow of events in Table 1.

\subsection{Noncontractible efforts and innovation}

Following Eggleston (2008), we assume that when the manager exerts effort $a$ to turn ideas $e$ and $i$ into reality, implementation is successful with probability $\lambda(a)$. Assume $a \in[0, \infty)$; $\lambda(0)=0 ; \lambda(\infty)=1 ; \lambda^{\prime}(a)>0 ;$ and $\lambda^{\prime \prime}(a)<0$. Effort $a$ is observable but not contractible and has a constant marginal cost of 1 .

Effort costs are $e+i$ and result in blueprints. The manager bears costs directly. Cost innovations reduce costs by $c(e)$, so if $e$ is implemented successfully costs are reduced to $C=C_{0}-c(e)$. As in HSV, we assume diminishing returns to cost control: $c(0)=0$; $c^{\prime}(0)=\infty ; c^{\prime}>0 ; c^{\prime \prime}<0$.

Quality, initially $B_{0}$, depends on both cost control and quality improvement. Changes that reduce service costs - such as recruiting less expensive and less qualified staff or lax infection control - may reduce quality; this damage is captured by the function $b(e)$. Quality innovations, net of their associated costs, increase quality by $\beta(i)$. Thus if $e$ and $i$ are successfully implemented, quality $B$ becomes

$$
B=B_{0}-b(e)+\beta(i)
$$

As in HSV, we assume $b(0)=0 ; b^{\prime} \geq 0 ; b^{\prime \prime} \geq 0 ; \beta(0)=0 ; \beta^{\prime}(0)=\infty ; \beta^{\prime}>0$; and $\beta^{\prime \prime}<0$.

The total surplus generated by ideas not included in the original contract is $S=\beta(i)-$ 
$b(e)+c(e)$. Following HSV we assume $-b^{\prime}(e)+c^{\prime}(e)>0$ over the relevant range (that is, quality damage from cost control offsets, but never completely outweighs, the efficiencies associated with appropriate cost control). The socially efficient outcome would be achieved if $\mathrm{M}$ chose efforts $e, i$, and $a$ according to

$$
\begin{aligned}
\lambda\left(a^{*}\right)\left[-b^{\prime}\left(e^{*}\right)+c^{\prime}\left(e^{*}\right)\right] & =1, \\
\lambda\left(a^{*}\right) \beta^{\prime}\left(i^{*}\right) & =1, \\
\lambda^{\prime}\left(a^{*}\right)\left[\beta\left(i^{*}\right)-b\left(e^{*}\right)+c\left(e^{*}\right)\right] & =1 .
\end{aligned}
$$

The socially efficient levels of cost and quality innovations, $e^{*}$ and $i^{*}$, and implementation effort, $a^{*}$, equate their expected net contributions to social welfare with their marginal cost of 1 .

However, when innovations are not contractible (or, for various reasons, omitted from the contract even if technically contractible), M's choices of $e^{*}, i^{*}$, and $a^{*}$ depend on M's expectation of a reward for excellent performance or of a "bail out" despite poor performance. In other words, incentives for innovation depend on the level of appropriation of surplus (magnitude of $m$ ) and the expected softness of the budget constraint.

\subsection{Defining the softness of budget constraint}

With probability $(1-\lambda(a))$, M's effort $a$ was insufficient to turn the promised changes $e$ and $i$ into reality, and performance is weak. Can M rationally expect to be able to continue business as usual despite this performance (i.e., does $\mathrm{M}$ face a soft budget constraint)?

The owners and payers, through refusing to contract, may force closure of the facility. The liquidation value, $L>0$, fluctuates with variations in the market value of the land, equipment, brand/reputation, and all other associated nonhuman assets. One can think of $L$ as being drawn from a probability distribution $F(L)$.

Let $\sigma$ be the expected probability that $V_{o}>L$, the ex post probability that the facility 
continues to operate despite weak performance:

$$
\sigma \equiv \operatorname{Pr}\left[V_{o}>L\right]
$$

$\sigma$ represents the softness of the budget constraint. If $\sigma=1$, the budget constraint is extremely soft: the facility never faces closure despite M's low effort, since $V_{o}>L$ always holds true. At the other extreme if $\sigma=0$, the budget constraint is very hard: failure to implement innovations always leads to closure (even if the manager exerted considerable effort but was unlucky), since $L>V_{o}$ for every realization of $L$. More generally, the provider will expect some probability of continuation, $0 \leq \sigma \leq 1$.

In equilibrium, the manager's expectation $\sigma$ equals the true likelihood of a bail out versus closure. For example, perhaps the manager of a large teaching hospital that is a member of a hospital system would be justified to expect that poor financial performance in one or two years would not immediately lead to closure. In contrast, equally poor performance at a small non-teaching, non-system hospital in a competitive urban market might be associated with high probability of closure. The latter hospital manager faces a harder budget constraint.

This suggests that an appropriate metric for a hospital's softness of budget constraint $(\sigma)$ would be the inverse of the probability of closure $(1-\sigma)$. Our empirical analysis employs this proxy for SBCs.

\subsection{How SBCs Shape Innovation Incentives}

SBCs dampen the manager's ex ante incentive to invest in innovations. This effect is salutory if hard budget constraints would have induced over-investment, such as excessive cost control and its associated damage to noncontractible quality. To see how the simple model predicts 
this result, consider that M's overall expected payoff is

$$
\begin{aligned}
U= & P_{o}-C_{o}-e-i-a+\lambda(a)\left(m S+U_{o}\right) \\
& +(1-\lambda(a))\left[\sigma U_{o}+(1-\sigma) U_{L}\right] .
\end{aligned}
$$

M chooses innovations and implementation effort according to

$$
\begin{aligned}
\lambda(a) m\left[-b^{\prime}(e)+c^{\prime}(e)\right] & =1, \\
\lambda(a) m \beta^{\prime}(i) & =1, \text { and } \\
\lambda^{\prime}(a)\left[m S+(1-\sigma)\left(B_{o}-U_{L}\right)\right] & =1 .
\end{aligned}
$$

Our focus is on how M's choices of $e$ and $i$ are shaped by the softness of budget constraint, $\sigma$.

Proposition 1 (SBCs and cost control) Softer budget constraints are associated with less cost control: $\frac{d e}{d \sigma}<0$.

Proof. Differentiating first-order condition (5), we find that

$$
\frac{d e}{d \sigma}=\frac{-\frac{d \lambda}{d a} \frac{d a}{d \sigma}\left[-b^{\prime}(e)+c^{\prime}(e)\right]}{\lambda(\sigma)\left[-b^{\prime \prime}(e)+c^{\prime \prime}(e)\right]}<0
$$

The denominator is negative by the second order condition and the numerator is positive because $\lambda^{\prime}(a) \frac{d a}{d \sigma}<0$ (see Eggleston 2008) and by assumption $-b^{\prime}(e)+c^{\prime}(e)>0$.

Proposition 1 predicts that hospitals facing softer budget constraints will be associated with less aggressive cost control and generally higher costs. The full range of cost control efforts may be difficult for researchers to observe and quantify. One way to test the prediction is to assess the impact of SBCs on service offerings which are potentially contractible but not actually contracted upon. If SBCs are associated with continually offering services known to be generally unprofitable, then it is even more likely that SBCs would be associated with 
other, less quantifiable cost containment efforts, including those that potentially damage hard-to-observe aspects of quality.

The association between softness of budget constraints and lower cost control derives from a model that is agnostic about why payers and owners allow a soft budget constraint equilibrium to persist. The logic of the proposition is only further reinforced, however, if one considers that providing access to unprofitable safety net services is a common justification for softening of budget constraints. In other words, a hospital's provision of safety net services can be used to argue for giving the hospital itself a financial "safety net" to prevent closure.

Unlike the prediction that SBCs are associated with higher costs, the impact of SBCs on quality is less clear-cut.

Proposition 2 (SBCs and quality) The impact of softness of budget constraint on quality is theoretically ambiguous: $\frac{d B}{d \sigma} \lessgtr 0$. If $-b^{\prime}(e) \frac{d e}{d \sigma}>\left|\beta^{\prime}(i) \frac{d i}{d \sigma}\right|$, then $\frac{d B}{d \sigma}>0$ (soft budget constraints are protective of quality when there is large scope for cost control to compromise quality).

Proof. Quality is $B=B_{0}-b(e)+\beta(i)$. We previously showed that $\frac{d e}{d \sigma}<0$. Thus softening a budget constraint reduces quality damage from cost control, but also reduces quality improvement:

$$
\frac{d i}{d \sigma}=\frac{-\frac{d \lambda}{d a} \frac{d a}{d \sigma} \beta^{\prime}}{\lambda(\sigma) \beta^{\prime \prime}}<0
$$

The net impact on quality depends in the relative magnitude of these two effects:

$$
\begin{aligned}
\frac{d B}{d \sigma}= & -b^{\prime}(e) \frac{d e}{d \sigma}+\beta^{\prime}(i) \frac{d i}{d \sigma} \lessgtr 0 . \\
& -(+)(-)+(+)(-)
\end{aligned}
$$


SBCs increase costs and lower quality innovations, but also reduce damage to noncontractible quality from overly zealous cost control. The net impact on service quality is ambiguous. Two empirically testable implications follow. First, the magnitude of the association between softness of budget constraint and quality is likely to be smaller than that between SBCs and cost control, because of the offsetting effect of decreased quality improvement innovations. Second, SBCs are protective of quality only when SBCs significantly

impact cost control $\left(\frac{d e}{d \sigma}<0\right)$ and when there is large scope for damage to quality from noncontractible aspects of cost control $(-b(e)$ is large). We use the example of heart attack mortality as an aspect of quality that might be particularly appropriate for empirically measuring noncontractible hospital quality and testing its association with softness of budget constraints.

In sum, we can define softness and hardness of budget constraints relative to the optimal probability of closure, $\sigma^{*}$; budget constraints are soft when equilibrium $\sigma$ is such that $1 \geq \sigma>\sigma^{*}$. SBCs imply low implementation effort $a\left(\frac{d a}{d \sigma}<0\right)$, low likelihood of implementing innovations $\left(\frac{d \lambda}{d \sigma}=\lambda^{\prime}(a) \frac{d a}{d \sigma}<0\right)$ and inefficiently low cost control efforts $\left(e<e^{*}\right.$; see Eggleston 2008). Conversely, a budget constraint is said to be hard when $\sigma^{*}>\sigma \geq 0$. Overly hard budget constraints stimulate high implementation effort $\left(a>a^{*}\right)$, high likelihood of realizing the surplus from innovations $\left(\lambda>\lambda^{*}\right)$, and excessively high cost control $\left(e>e^{*}\right)$ which can damage difficult-to-observe aspects of quality. Propositions 1 and 2 summarize our theoretical predictions.

\section{Data and Statistical Methods}

\subsection{Data sources and Sample}

Our primary data sources are the American Hospital Association (AHA) annual surveys and hospital cost reports from the Centers for Medicare and Medicaid Services (CMS) between 
1990 and 2005. The two data sources together provide rich information on hospital financial, utilization, and service characteristics. In addition, to construct the SBC metric, we obtained hospital closure data (1990-2000) that identifies the year and nature of hospital closure from the National Bureau of Economic Research, where the underlying data is the AHA surveys. For the AMI mortality analysis, we obtained hospital-specific risk-adjusted AMI mortality rates between 1994 and 2004 from Jonathan Skinner of Dartmouth College. The underlying data source for the mortality rates is the Medicare MEDPAR data.

We further supplement the hospital data with other information to capture relevant market characteristics. These include the area wage index from the PPS Impact File, population characteristics from the Area Resource File, economic conditions from the County Business Patterns, county property tax from the Census of Government Finance, and a variable-radius hospital competition measure (Herfindahl index, provided by Glenn Melnick of USC).

As discussed in the conceptual framework, we use the inverse of expected probability of closure as a proxy for the degree of budget constraint softness. We exclude the following hospitals to develop a "clean" metric for SBCs in the analytic sample. First, we exclude hospitals that converted ownership to avoid the potential confounding of ownership conversion with closure. Second, we exclude hospitals that were acquired by another hospital (instead of shut down completely). Descriptive analysis suggests that acquired hospitals tend to be financially better off before the acquisition than the average hospital and are quite different from hospitals that were shut down completely. Since SBCs refer to organizations that receive infusion of funds to stay afloat, not organizations rewarded for above-average performance, excluding acquired hospitals when estimating the SBC metric is most consistent with our conceptual framework.

To test Proposition 1, we examine whether SBCs are associated with lower hazard of shutting down safety net services. For this service survival analysis, our sample includes all general, acute, short-stay hospitals between 1990 and 2005 with one exception: we exclude hospitals that were shut down as identified in our closure data (i.e., we only estimate service 
survival among hospitals that continue to operate beyond 2000). Our analysis utilizes all 16 years of information for all services except AIDS treatment: AIDS service data are available only for the 1994-2005 period. Since we are concerned with adoption and shut down decisions, panel data spanning 16 years should provide us with sufficient information to carry out the analysis.

For empirical test of Proposition 2, we examine the association between SBCs and quality using the risk-adjusted AMI mortality data as a proxy for noncontractible quality. In that analysis, our sample includes all general, acute, short-stay hospitals between 1994 and 2004. As for the service survival analysis, we exclude hospitals that were shut down completely before 2000. In addition, we exclude hospitals with fewer than 20 AMI admissions in a year because CMS regulations stipulate that the hospital-level mortality rates are only publicly released for hospitals with at least 20 AMI admissions per year.

\subsection{Statistical methods overview}

Our empirical model consists of two stages. In the first stage, we develop a SBC index for each hospital. Then in the second stage we estimate the effect of SBCs on access and quality. For the access analysis, we estimate the effect of SBCs on safety net service survival using discrete-time proportional hazard models (Prentice and Gloeckler 1978; Baker 2001; Baker and Phibbs 2002; Shen 2008). The SBC index we develop in the first stage becomes the key independent variable in the discrete time proportional hazard models. Our survival analysis estimates the effect of SBCs on shut down rates of four safety net services: inpatient substance abuse treatment, outpatient substance abuse treatment, HIV/AIDS treatment, and emergency departments. For the quality analysis, we estimate the effect of SBCs on AMI mortality rates using generalized least square models (Greene, 2003; McClellan and Staiger 2000; Shen 2002). The AMI mortality measures we analyze include 30-day, 90-day, and 1-year mortality rates.

For both the access and quality analyses, we use boot strapping methods to obtain 
standard errors corrected to account for the fact that the SBC measure is derived from the first stage regression. We also compare the estimated effect of our SBC index on access and quality with the estimated effect of profit margin to contrast the two different concepts of hospital financial health.

The rest of the methods section is divided as follows. First, we present the analytical model used to come up with the SBC metric. Second, we provide more detail on the analytical models for the service survival analysis. Lastly, we describe the estimation models for the mortality analysis, including how the risk-adjusted mortality rates are aggregated to the hospital level.

\subsubsection{Estimating the softness of budget constraints}

While profit margins in the current and previous years are one important component of overall financial health and thus factor into measuring the softness of budget constraint, the key difference between the profit margin and SBC measures is that the latter takes into account hospitals' expected future financial outlook in the face of uncertainty about performance, as discussed in the conceptual framework. A quintessential measure of a hard budget constraint is whether the organization risks going out of business when it does not meet performance expectations (Kornai 1986; Kornai, Maskin, and Roland 2003). We use data on hospital closures through 2000, available from the NBER, to construct this measure of SBC with the following steps. First, we estimate a model of determinants of closure based on prior literature (Sloan et al 2003; Chakravarty et al 2006) and our conceptual framework. In particular, we estimate a probit model of the probability of closure in a given year as a function of the following hospital and market characteristics ${ }^{3}$ :

- Hospital internal financial health: these include the current and previous year's operating margins, as well as an indicator for whether the hospital reports negative net

\footnotetext{
${ }^{3}$ All continiuous variables are normalized so that they represent deviations from the yearly average. This allows us to project the SBC measures for 2001-2005 without worrying about which year is used as the reference year.
} 
income in the current and previous year;

- Hospital organizational characteristics such as ownership (not-for-profit, for-profit, government), location (urban, rural), teaching status, and system membership;

- Hospital size as measured by total inpatient and outpatient volumes;

- Hospital external financial environment: these include county property tax per capita as well as interactions with hospital ownership. The idea of including the county property tax variable is that counties with higher property taxes might be able to provide better financial cushions to public hospitals and have potential spillover effects on other hospitals in the same county.

- Demand for health care: following Chakravarty et al (2006), we try to capture demand for health care by using the elderly population as our measure of exogenous demand shifts. The elderly are heavy consumers of health care, so changes in the percent of elderly population should be highly correlated with changes in the demand for hospital services, which in turn would influence decisions about hospital closure.

- Other market characteristics: these include county population and per capita income, percent of for-profit and government hospitals within a 15-mile radius of a hospital's zip code, and a hospital competition measure (Herfindahl index).

Second, using the models' coefficients, we construct the predicted probability of closure for 1990-2005 for all hospitals that are in continuous operation between 1990 and 2000. Note that for 2001-2005, we are essentially predicting out of sample since closure information is only available through 2000. Hospitals with higher predicted probability of closure, conditional on a given financial pressure or market competitiveness, are considered to be facing a harder budget constraint. We take the complement of this predicted probability as the measure of $S B C$, so this measure takes on a higher value if hospitals face softer budget constraints. For ease of interpretation and to be consistent with the profit margin 
measures used by prior literature, we convert this continuous measure of $S B C$ into a 5-level index by taking the quintiles of the continuous variable. The quintiles of the $S B C$ measure will become the key independent variables in the second stage analysis of hospital access and quality. The identification variables for $S B C$ are essentially the four internal financial health variables, the demand for health care, and the three external financial environment variables (i.e., these variables are not included in the second stage models).

\subsubsection{Analysis of Safety Net Service Survival}

Defining Dependent Variables. Our service survival analysis focuses on services that are commonly viewed as safety net services. Based on IOM (2000) and Zuckerman et al (2001), the safety net services we investigate include inpatient substance abuse services, outpatient substance abuse services, HIV/AIDS treatment, and emergency department. ${ }^{4}$ One limitation of AHA data is that there are missing values over the years, especially toward the later years. When hospitals did not report whether they offered a service in a given year, we impute the values using information from one year before the missing year (for example, if a hospital is missing a 1992 value but reported having a given service in 1991 and 1993 , we would impute 1992 as having such a service).

Because we are essentially estimating a duration model, we need to track when hospitals start and stop offering each service. With the cleaned AHA data, we construct adoption and exit variables for each of the services. We use the adoption definition in Baker and Phibbs (2002) — we define the adoption year as the first year of the first consecutive pair of years in which the hospital says it offers a given service. Using this definition is more conservative than defining the adoption year as the first year that a hospital says it offers a given service, since it minimizes sporadic reporting errors. Because the data series starts in 1990, if a hospital reports having a given service in both 1990 and 1991, then the adoption year would

\footnotetext{
${ }^{4}$ There are other safety net services (such as burn units and neonatal intensive care) that we exclude because we do not have enough sample size to analyze the shut down decisions of these services (neonatal intensive care, for example, requires such a high sunk cost that hospitals rarely shut it down).
} 
be 1990. Exit years are defined using the following logic: (1) there must be an adoption year between 1990 and 2003; (2) the exit year is the year after the last year in which the hospital offers a given service. Because we use the more conservative adoption definition, this means that the earliest exit occurs in 1992 (while the earliest adoption year is 1990).

Statistical Methods. To estimate the effect of a hospital's expected overall financial health on the hazard of safety net service shut down, we limit our hospitals to only those that are in continuous operation between 1990 and $2000^{5}$ and did not change ownership during this period. Since the proportional hazard framework is nonparametric, we do not have to assume a priori whether the exit rate distribution has a positive or negative dependence on time. Since not all hospitals are at risk of shutting down a given service, only those who have adopted the service are included in the hazard model. Specifically, all hospitals that already offered the service by 1990 will enter the model in 1990. If a hospital did not adopt a service until 1994, then it does not enter the hazard model of exit rate until 1994. If a hospital never offered a service, then it is not included in the model.

We define 14 intervals during which we can observe service exit. Suppose a hospital adopted a given service in year $t_{0}$. Then intervals $\left(t_{0}, t_{2}\right],\left(t_{2}, t_{3}\right],\left(t_{3}, t_{4}\right]$, and so on capture hospitals that offered a given service in the beginning year of that interval but dropped the service by the end year of the interval. Hospitals that adopted a service during the study period but did not drop that service by the end of 2005 will be censored at 2005. Note that for hospitals that adopted a given service after 1990, there will be fewer than 14 intervals. The probability that hospital $i$ drops service $j$ given that service $j$ was offered up until time $t$ is described by the following hazard function:

$$
\lambda_{i j}(t)=\exp \left(-\left(\beta_{1 j} F I N_{i t}+\beta_{2 j} O W N_{i t}+\beta_{3 j} X_{i t}\right)\right) \lambda_{0 j}(t)
$$

\footnotetext{
${ }^{5}$ If a hospital appears in both 1990 and 2000, we assume it is in continuous operation during this period.
} 
where $\lambda_{0 j}(t)$ is the baseline hazard rate for service $j$, which differs by the four Census regions; FIN $N_{i t}$ measures the hospital's financial health (defined below); $O W N_{i t}$ is a categorical variable that captures hospital ownership (for-profit, government; with not-for-profit as the reference group); and $X_{i t}$ is a vector of hospital and market characteristics, including system membership, urban indicator, hospital competition, case mix index, hospital size (as measured by inpatient discharges and outpatient visits), county population, per capita income, and percent for-profit and government hospitals within a 15-mile radius.

In the first model, the variable $F I N_{i t}$ is quintiles of the SBC measure as defined in the first stage. The lowest quintile (i.e., hospitals facing the hardest budget constraints) serve as the reference group. In the second model, for comparison purposes, we use quintiles of average profit margin as a measure of FIN. Using the quintiles instead of the continuous version of the variables allow us to capture possible nonlinear relationships between financial health and service survival, as well as easier interpretation of the results.

The primary coefficient of interest is $\beta_{1 j}$, which tests Proposition 1 and captures the effect of financial health on the hazard of exit for the $j^{\text {th }}$ service. The coefficients can be estimated using discrete-time proportional hazard models originally proposed by Prentice and Gloeckler (1978). We allow the baseline hazard rate to vary by the four Census regions. In presenting the results, we use hazard ratios instead of the actual coefficients for ease of interpretation: Since a higher value of $S B C$ indicates a softer budget constraint, a hazard ratio below 1 indicates a lower risk of exit for hospitals with softer budget constraints, compared to hospitals facing harder budget constraints.

In all survival model estimations involving SBC measures, we obtain the standard errors by bootstrapping methods. In particular, we estimate the two stages jointly in 1000 bootstrap replications and compute the standard errors based on the 1000 bootstrap samples. 


\subsubsection{Analysis of AMI Mortality Rates}

Defining Dependent Variables. For the AMI mortality analysis, we examine 30-day, 90day, and 1-year mortality rates from the Medicare fee-for-service population. The aggregated hospital-specific outcome measures were constructed and supplied by Jonathan Skinner at Dartmouth College. These measures were derived from patient-level regressions that include hospital indicators and fully interacted patient demographic covariates (five age groups, gender, race, and urban or rural residence) as well as 17 comorbidity measures to control for severity of the illness (full details are described in Skinner and Staiger, 2008). In other words, instead of using the actual percentage of patients who die in each hospital as the outcome measures, we use these hospital intercepts obtained from the patient-level regressions. These hospital intercepts represent the mean value of outcomes for each hospital holding patient characteristics constant across all hospitals. These hospital-specific outcome measures are normalized so that the average value is zero for each year. For example, a 0.01 mortality rate would indicate that the mortality rate for such a hospital is 1 percentage point above the average hospital in that given year.

Statistical Methods. We estimate the relationship between the financial measures and AMI mortality rates using the following model:

$$
Q_{i j t}=\alpha_{0 j t}+\alpha_{1 j} F I N_{i t}+\alpha_{2 j} O W N_{i j t}+\alpha_{3 j} X_{i j t}+\xi_{i j t},
$$

where $Q_{i j t}$ is the AMI mortality outcome $j$ in hospital $i$ at year $t$; and the rest of the independent variables are defined the same way as in the service survival models. We estimate this equation using the generalized least square (GLS) method (Greene 2003; Shen 2003). The GLS estimate is:

$$
\alpha=\left(X^{\prime} G^{-1} X\right)^{-1}\left(X^{\prime} G^{-1} Q\right)
$$


where $\mathrm{G}$ is a $\mathrm{JT} \times \mathrm{JT}$ diagonal block variance-covariance matrix of the disturbance vector, $\xi$, where each block is a $\mathrm{T} \times \mathrm{T}$ variance-covariance matrix corresponding to an individual hospital. The matrix G follows a non-stationary first-order autoregression structure (AR1), and is weighted according to how noisy the quality measure is for a given hospital (a larger hospital, as measured by the total AMI admissions, gets more weight because outcome measures are less noisy in a bigger hospital than in a smaller hospital). As with the service survival analysis, we estimate the two stages jointly using bootstrapping methods to obtain the standard errors.

\section{Results}

\subsection{Descriptive Analysis}

In Table 2, we provide the descriptive statistics of study variables for the whole sample, as well as by SBC category (Appendix A1 presents the results of our first stage estimation upon which the SBC categories are based). Hospitals in different SBC categories are quite different along many dimensions. In describing the results, we focus our comparison on hospitals in the hardest and the softest budget constraint categories $(<20$ th percentile and $>80$ th percentile of the $S B C$ index). Not surprisingly, hospitals in the softest budget constraint category have higher profit margins (0.03 compared to -0.11 for hospitals facing the hardest budget constraints). They are less likely to be for-profit (only 4 percent compared to 20 percent in the lowest SBC category) but are more likely to be part of a system (60 percent vs. 39 percent). They tend to be located in more concentrated markets (Herfindahl index 0.41 compared to 0.3), and are much larger hospitals (as measured by total inpatient discharges and outpatient visits). Hospitals in the softest budget constraint category also have a better external financial environment: the county property tax per capita is almost $\$ 900$ compared to $\$ 718$ among hospitals in the lowest SBC category. However, per capita income is quite 
comparable across the SBC categories.

Figure 1 compares the cumulative survival probability of outpatient substance abuse services by SBC categories and by profit margin categories. By default, all hospitals start with 100 percent survival probability at time $t_{0}$. Figure 1 illustrates that our $S B C$ metric indeed measures something different from the hospital's average profit margin over the studied period. The cumulative survival probability of outpatient substance abuse services is higher in hospitals with the lowest profit margins $(<20$ th percentile, solid line $)$ than those in the highest profit margin category (>80th percentile, dashed line). Even though higher profit is associated with softer budget constraints as Table 2 shows, the survival probability is higher in hospitals with the softest budget constraints (>80th percentile of SBC distribution, dashed line) than those with the hardest budget constraints (<20th percentile, solid line). ${ }^{6}$ This finding is nevertheless completely consistent with our conceptual framework: hospitals may achieve higher profits by shutting down unprofitable safety net services (a form of cost control). However, cost control is lower (and service survival higher) among those hospitals which are "too big to fail" in the sense of rationally expecting continued operations even if profits are low.

Figure 2 shows the normalized risk adjusted AMI 1-year mortality rates between 19942004 by the same categories of financial health as in Figure 1. In this case, hospitals with higher profit and facing softer budget constraints have lower mortality rates than hospitals with low profit margins and hard budget constraints. As Proposition 2 highlights, the impact of SBCs on quality is theoretically ambiguous. Finding that SBCs improve service survival, as noted above, suggests that cost control on both observable and unobservable dimensions, which can compromise quality, may be considerably more aggressive in hospitals facing harder budget constraints. If the magnitude of this quality-shaving effect is strong enough, a SBC is protective of noncontractible quality, as we find in Figure 2.

\footnotetext{
${ }^{6}$ Figures from other services show similar patterns and are available upon request.
} 


\subsection{Effect of Financial Health on Hospital Access and Quality}

Tables 3 and 4 present the estimation results for the financial measures of equations (6) and (7), respectively. The full results for all outcomes are presented in Appendix A2 (for safety net services) and A3 (for AMI mortality). The top panel of Table 3 presents the results from using the SBC index as the financial health proxy, and the bottom panel presents the results using profit margin; likewise for Table 4.

Analysis of Safety Net Services. For the service survival analysis, we present the estimation results as hazard ratios. Take the comparison between hospitals in the lowest and the highest SBC category, for example. The hazard ratio is the ratio of the hazard rate between these two groups, where the hazard rate is the probability that service $j$ will be dropped in year $t+1$ given that it was provided in year $t$. The reference group (hospitals facing the hardest budget constraint) has a hazard ratio of 1 by default. A statistically significant hazard ratio below one indicates a lower risk of service shut down in the softest SBC categories compared with the reference group. The first column shows that the hazard rate of shutting down inpatient substance abuse treatment decreases as hospitals move up the soft budget constraint categories. For example, the hazard of shutting down this service is 0.65 lower in hospitals with the 2 nd softest $\mathrm{SBC}$ index $(\mathrm{p}<0.10)$ compared to the reference group, and is 0.56 lower in hospitals with the softest budget constraint $(\mathrm{p}<0.05)$. This pattern is observed in the other 3 safety net services as well.

The SBC index is not merely capturing standard financial health measures such as profit margin. When we replace the SBC measure with the profit margin categories in the bottom panel, we observe the opposite effect. In general, hospitals with higher profit margins are more likely to shut down safety net services, perhaps as a way to protect their profit margins. The SBC also is not merely capturing ownership differences, but appears independently to explain some of the variation between and within ownership forms. ${ }^{7}$

\footnotetext{
${ }^{7}$ Hospital ownership is not a significant predictor in the first stage estimation of the SBC index. Appendix
} 
Analysis of Mortality Rates. For the mortality analysis, we present the estimation results as coefficients. The first column of Table 4 shows that 30-day mortality rates are 0.5 percentage point lower in hospitals with SBC in the $20-40$ th percentile compared to the reference group, hospitals with the hardest budget constraints. The magnitude increases by the SBC percentiles: the 30-day mortality is 1 percentage point lower in hospitals with the softest budget constraints ( $\mathrm{SBC}>80$ th percentile) compared to the reference group. In all 3 mortality rates examined, the mortality rates decrease as hospitals move up the SBC categories (with the largest decrease in mortality when hospitals move out of the lowest quintile, that is, away from being on the margin of closure). All coefficients are statistically significant at the 0.01 level. The bottom panel of Table 4 shows a similar pattern when we replace the SBC measure with profit margin quintiles, although the magnitude is slightly smaller for 30-day and 90-day mortality rates. Similar to the safety net service results, the SBC also is not merely capturing ownership differences: all three mortality rates are higher in for-profit and government hospitals, by about 1 percentage point, compared to not-for-profit hospitals after we control for SBC.

Sensitivity Analysis. Our results appear to be stable under various alternative specifications. One potential problem with the hazard model is that the results might be driven by differences between early and late adopters of the services (since we do not observe hospitals before 1990). If the timing of adoption varies systematically across the financial health categories, the results regarding SBC impact on service shut down would be confounded with the timing of service adoption. There is no known analytical solution to this problem, but to test the sensitivity of our results, we re-estimate equation (6) by including an indicator for early adopter, which takes on the value of 1 if the hospital already offered a given service A2 shows that conditional on the level of the SBC index, for-profit hospitals have higher hazard of shutting down most of the safety net services than not-for-profit hospitals do (the hazard rate of for-profit hospitals is 1.2-2.18 times higher than that of not-for-profit hospitals). Government and not-for-profit hospitals have comparable hazards of shutting down safety net services, with the exception of inpatient substance abuse treatment where not-for-profit hospitals have the lowest hazard of shutting this service down. For more discussion focusing on ownership differences, see Shen and Eggleston (2008). 
by 1990 and 0 otherwise. Our results are stable under this alternative specification. Another limitation is that service variables are self-reported in the AHA surveys, so one might be concerned with data reliability. However, there is no reason to believe that reporting errors would be correlated with the budget softness indicator. To the extent that reporting errors might be correlated with hospital closure (poorer record keeping when facing financial hardship), limiting the sample to those that are in continuous operation could minimize this potential bias. We investigate whether our results are sensitive to this exclusion criteria by including all hospitals in an alternative estimation. Our results for both sets of analyses remain similar. Not surprisingly, the estimated effect of SBC is slightly larger in the safety net survival analysis when we also include hospitals that closed between 1990 and 2000 .

Our sample of AMI hospitals is skewed toward larger hospitals (since only hospitals with at least 20 AMI admissions are included). We try to assess the magnitude of the bias in the SBC effect due to this exclusion criteria by estimating the model separately for larger hospitals (those with at least 100 AMI admissions on average) and smaller hospitals (those with fewer than 100 AMI admissions). We noted that the magnitude of the SBC effect does not differ by the size of the hospitals after we control for volumes in the model. Lastly, we also test the stability of our results by giving equal weights to all hospitals, large or small. Again, the results remain stable under this alternative estimation.

\section{Conclusion}

In this paper, we introduce the concept of SBC (Kornai 1986) as an alternative financial measure of a hospital's overall financial health and offer an initial estimate of the empirical effect of SBCs on hospital access and quality. SBCs measure whether an organization can expect to be bailed out or to be left to fail if it consistently underperforms. Our conceptual model predicts that hospitals facing softer budget constraints will be associated with less aggressive cost control, and thus less likely to discontinue offering safety-net services. SBCs 
are predicted to be protective of quality when SBCs significantly impact cost control and there is large scope for damage to quality from noncontractible aspects of cost control. Our empirical finding that SBCs are associated with service offerings upholds the first prediction. We test the second prediction using heart attack mortality as an aspect of quality that might be particularly appropriate for revealing any quality-shaving cost control.

The contrasting results for SBC compared to profit margins in Figure 1 and Tables 3 and 4 clearly show that the SBC metric, defined as the inverse of the expected probability of hospital closure, captures not just a hospital's immediate financial situation but in some sense the "expected" longer-run effect. However, it is important to acknowledge the difficulty in establishing a clear empirical metric for softness of budget constraints, since there is little available data to capture exogenous variation. Our identification of the SBC metric comes from three sources: a hospital's internal financial health, external financial environment, and demand for health care. Even though the per capita property tax appears to be positively associated with softer budget constraints, there is little difference in percent elderly across the SBC categories (Table 2). Future work to refine the empirical SBC measure would further our understanding of the role of SBCs in the health care industry.

With this caveat in mind, our results still reveal some interesting and policy relevant insights. Even though a higher profit margin is positively correlated with softer budget constraints, softer budget constraints are associated with a lower probability of shutting down safety net services, whereas a higher profit margin is associated with a higher probability of shutting down safety net services (with the exception of emergency departments). The service survival results are consistent with the theoretical prediction that hospitals are more likely to maintain unprofitable services when facing softer budget constraints, because of the dampened incentive to engage in cost control innovations.

SBCs and profit margins have similar effects on AMI mortality rates, although the SBC effect has a slightly larger magnitude than the profit margin effect. The mortality analysis, testing Proposition 2, suggests that the dampened incentive for cost innovation as a result of 
a SBC (i.e., less zealous cost control) appears to outweigh the dampening effect on quality improvement innovation. This finding suggests that health care may be an area for which the scope for quality-damaging cost control is particularly large, and the inability to specify, monitor and enforce all aspects of quality should be an important consideration for policies that impact health care contracting and organization.

In addition, although not the focus of this paper, it is interesting to note that SBCs and hospital ownership explain different aspects of hospital operations: after controlling for softness of budget constraints, for-profits continue to have a higher hazard of shutting down some safety net services, and for-profit and government hospitals continue to have higher mortality rates compared to not-for-profit hospitals (Appendix A2 and A3). Future work to explore how SBCs differ across ownership forms and how effects may spill over among hospitals in a given market would be valuable, allowing insight into the "black box" of hospital performance differences. 


\section{References}

[1] Baicker K, and Staiger D. 2005. Fiscal shenanigans, targeted federal health care funds, and patient mortality. Quarterly Journal of Economics 120(1): 345-386.

[2] Baker LC. 2001. Managed care and technology adoption in health care: evidence from magnetic resonance imaging. Journal of Health Economics. 20(3):395-421.

[3] Baker LC, and Phibbs CS. 2002. Managed care, technology adoption, and health care: the adoption of neonatal intensive care. Rand Journal of Economics. 33(3):524-48.

[4] Bazzoli GJ, Chen HF, Zhao M, Lindrooth RC. 2008. Hospital financial condition and the quality of patient care. Health Economics. Aug;17(8):977-95.

[5] Chakravarty S, Gaynor M, Klepper S, and Vogt WB. 2006. Does the Profit Motive Make Jack Nimble? Ownership Form and the Evolution of the U.S. Hospital Industry. Health Economics. 2006 Apr;15(4):345-61

[6] Clement JP, Lindrooth RC, Chukmaitov AS, Chen HF. 2007. Does the patient's payer matter in hospital patient safety? Medical Care 45: 131-138.

[7] Cutler, D.M., 1995. The incidence of adverse medical outcomes under prospective payment. Econometrica 63, 29-50.

[8] Duggan MG. 2000. Hospital ownership and public medical spending. Quarterly Journal of Economics 115(4): 1343-1373.

[9] Eggleston K. 2008. Soft budget constraints and the property rights theory of ownership. Forthcoming in Economics Letters, http://dx.doi.org/10.1016/j.econlet.2008.03.010.

[10] Eggleston K. and Shen Y. 2008. Soft budget constraints and ownership: Empirical evidence from US hospitals. Working Paper. 
[11] Encinosa WE, Bernard DM. 2005. Hospital finances and patient safety outcomes. Inquiry. Spring;42(1):60-72.

[12] Greene, W. 2003. Econometric Analysis. Upper Saddle River, NJ: Prentice Hall.

[13] Hart O, Shleifer S, and Vishny RW. 1997. The proper scope of government: Theory and an application to prisons. Quarterly Journal of Economics 112(4): 1127-1161.

[14] Institute of Medicine. 2000. America's health care safety net: intact but endangered, Institute of Medicine.

[15] Lindrooth RC, Bazzoli GJ, Clement J. 2007. Hospital reimbursement and treatment intensity. Southern Economic Journal 73: 575-587.

[16] Kornai J. 1986. The softness of budget constraint. Kyklos 39(1): 3-30.

[17] Kornai J, Maskin ES, and Roland G. 2003. Understanding the soft budget constraint. Journal of Economic Literature 41(4): 1095-1136.

[18] McClellan, M., Staiger, D.O., 2000. Comparing hospital quality at for-profit and not-forprofit hospitals. In: Cutler, D.M. (Ed.), The Changing Hospital Industry: Comparing Not-for-Profit and For-Profit Institutions. University of Chicago Press, Illinois.

[19] Medicare Payment Advisory Commission (MedPAC). 2005. A Data Book: Healthcare Spending and the Medicare Program. MedPAC: Washington, DC.

[20] Morrisey MA. 2001. Competition in hospital and health insurance markets: a review and research agenda. Health Services Research 36(1, Part II): 191-221.

[21] Prentice R. and Gloeckler L. 1978. Regression analysis of grouped survival data with application to breast cancer data. Biometrics 34: 57-67.

[22] Shen, Y. 2002. The effect of ownership choice on patient outcomes after treatment for acute myocardial infarction. Journal of Health Economics 21 (5): 901-922. 
[23] Shen, Y. 2003. The effect of financial pressure on the quality of care in hospitals. Journal of Health Economics 22 (2): 243-269.

[24] Shen, Y. 2008. Do HMO and its for-profit expansion jeopardize the survival of hospital safety net services? Health Economics. Currently available at: http://www3.interscience.wiley.com/cgi-bin/fulltext/119882613/PDFSTART.

[25] Sloan FA, Ostermann J, and Conover CJ. 2003. Antecedents of hospital ownership conversions, mergers, and closures. Inquiry 40(1): 39-56.

[26] Staiger, D.O., Gaumer, G., 1992. Quality of care in hospitals: post-admission mortality under Medicare's Prospective Payment System. Working Paper (January).

[27] Volpp KG, Konetzka RT, Zhu J, Parson L, Peterson E. 2005. Effects of cuts in Medicare reimbursement on process and outcome of care for acute myocardial infarction patients. Circulation.112: 2268-2275.

[28] Zuckerman S, Bazzoli G, Davidoff A, LoSasso A. 2001. How did safety-net hospitals cope in the 1990s? Health Affairs 20(4): 159-168. 
Figure 1. Cumulative Survival Probability of Outpatient Substance Abuse Services
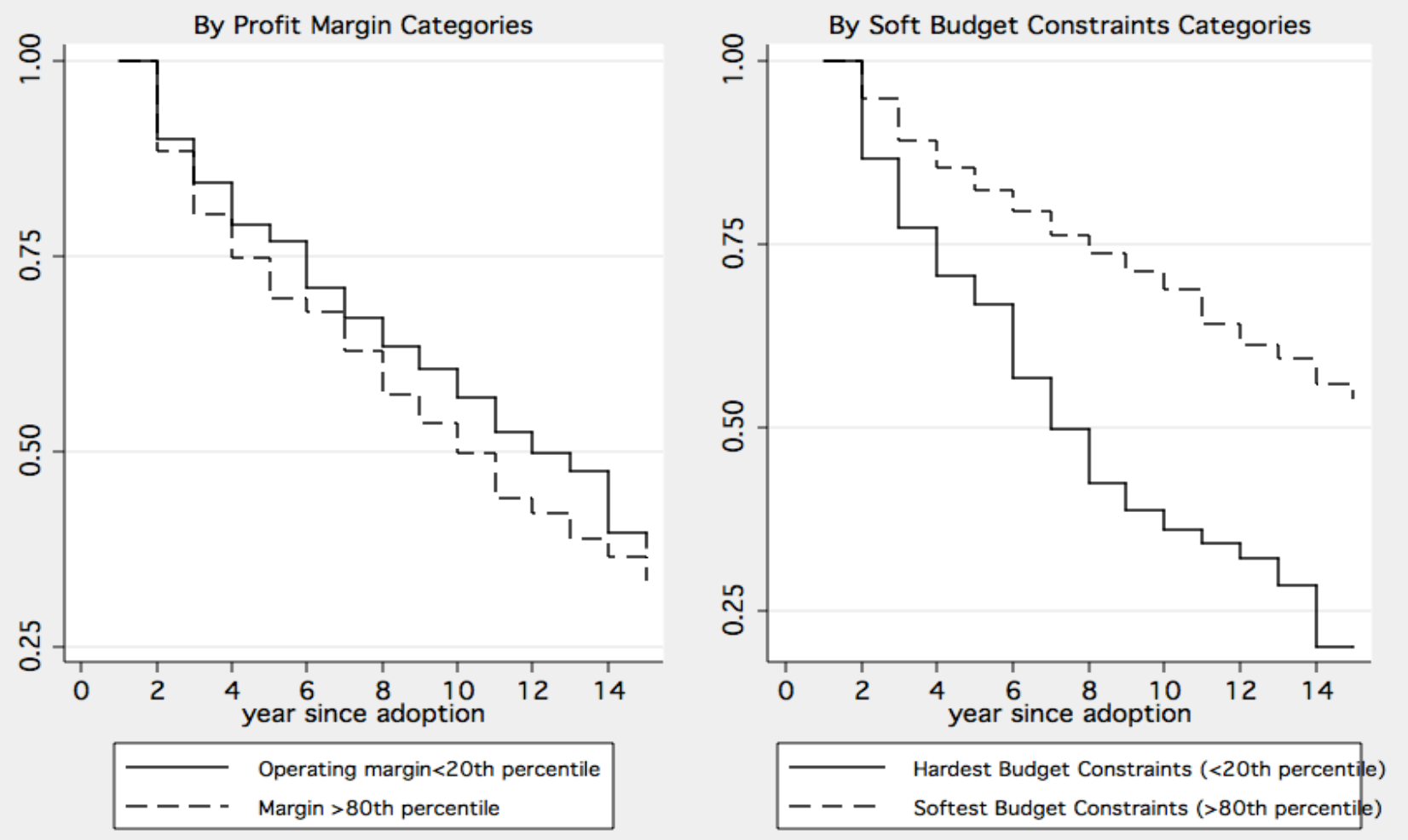

Figure 2. AMI 1-Year Mortality 1994-2004
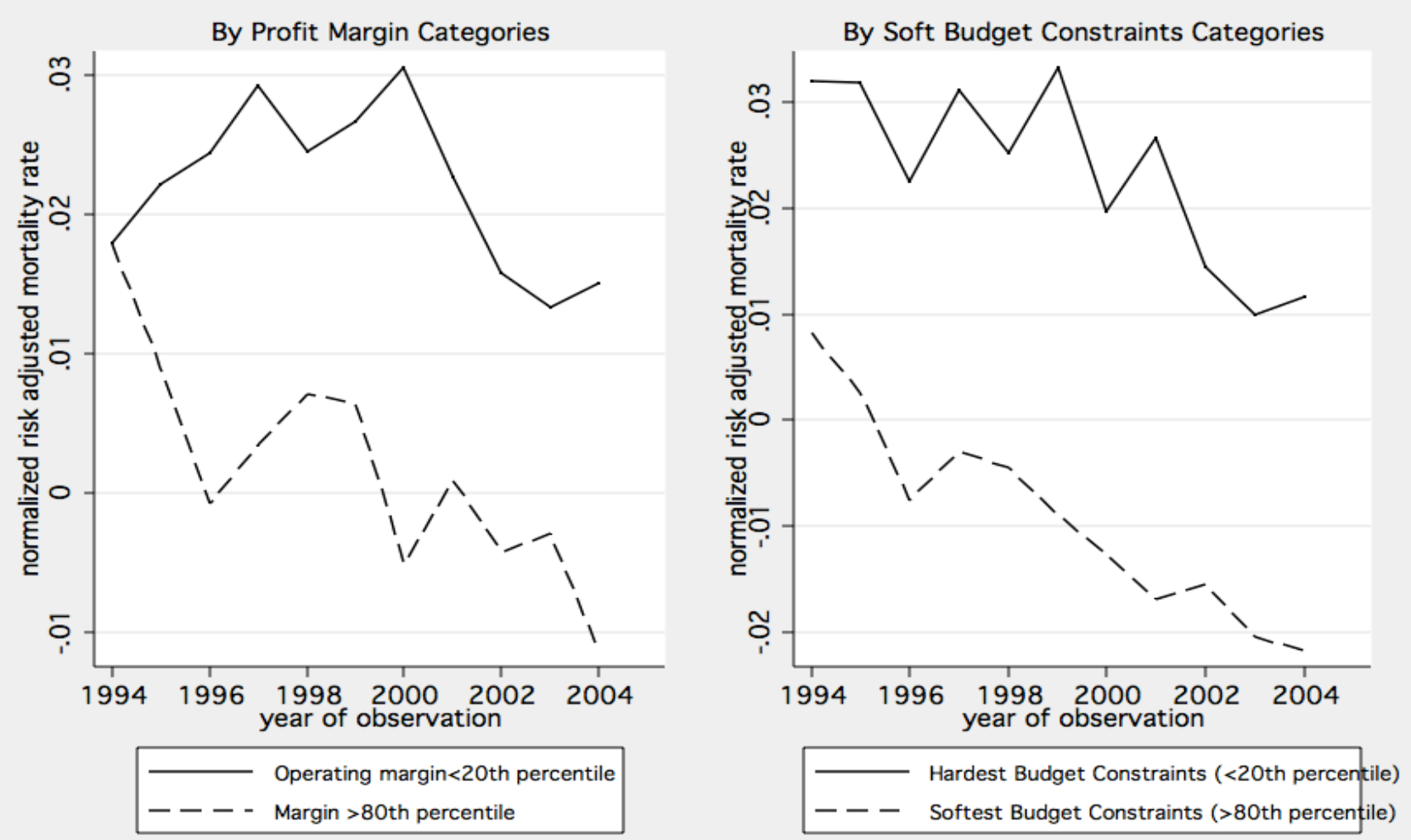
Table 1. THEORY OF SOFT BUDGET CONSTRAINTS AND INNOVATIONS:

Timeline AND PAYOFFS

\begin{tabular}{|c|c|c|c|}
\hline Date & Decisions & Manager M: $U$ & Owners and Payers: $V$ \\
\hline 0 & Contract for basic service package & $P_{o}-C_{o}$ & $B_{o}-P_{o}$ \\
\hline 0.5 & M invests in innovations $e$ and $i$ & $-e-i$ & \\
\hline 1 & Renegotiation over potential surplus, $S$ & Agree to receive $m S$ & Agree to $(1-m) S$ \\
\hline 1.5 & $\begin{array}{c}\text { Implementation effort } a \text {, } \\
\text { successful with probability } \lambda(a)\end{array}$ & $-a$ & \\
\hline 2 & $\begin{array}{l}\text { Divide } S \text { or, if implementation fails, } \\
\text { continue with probability } \sigma\end{array}$ & $\begin{array}{c}\lambda(a)\left(m S+U_{o}\right)+ \\
(1-\lambda)\left[\sigma U_{0}+(1-\sigma) U_{L}\right]\end{array}$ & $\begin{array}{c}\lambda(a)\left[(1-m) S+V_{o}\right]+ \\
\quad(1-\lambda) \max \left[V_{o}, L\right]\end{array}$ \\
\hline
\end{tabular}


Table 2. Descriptive Statistics of Study Variables By Soft Budget Constraints Categories 1990-2005

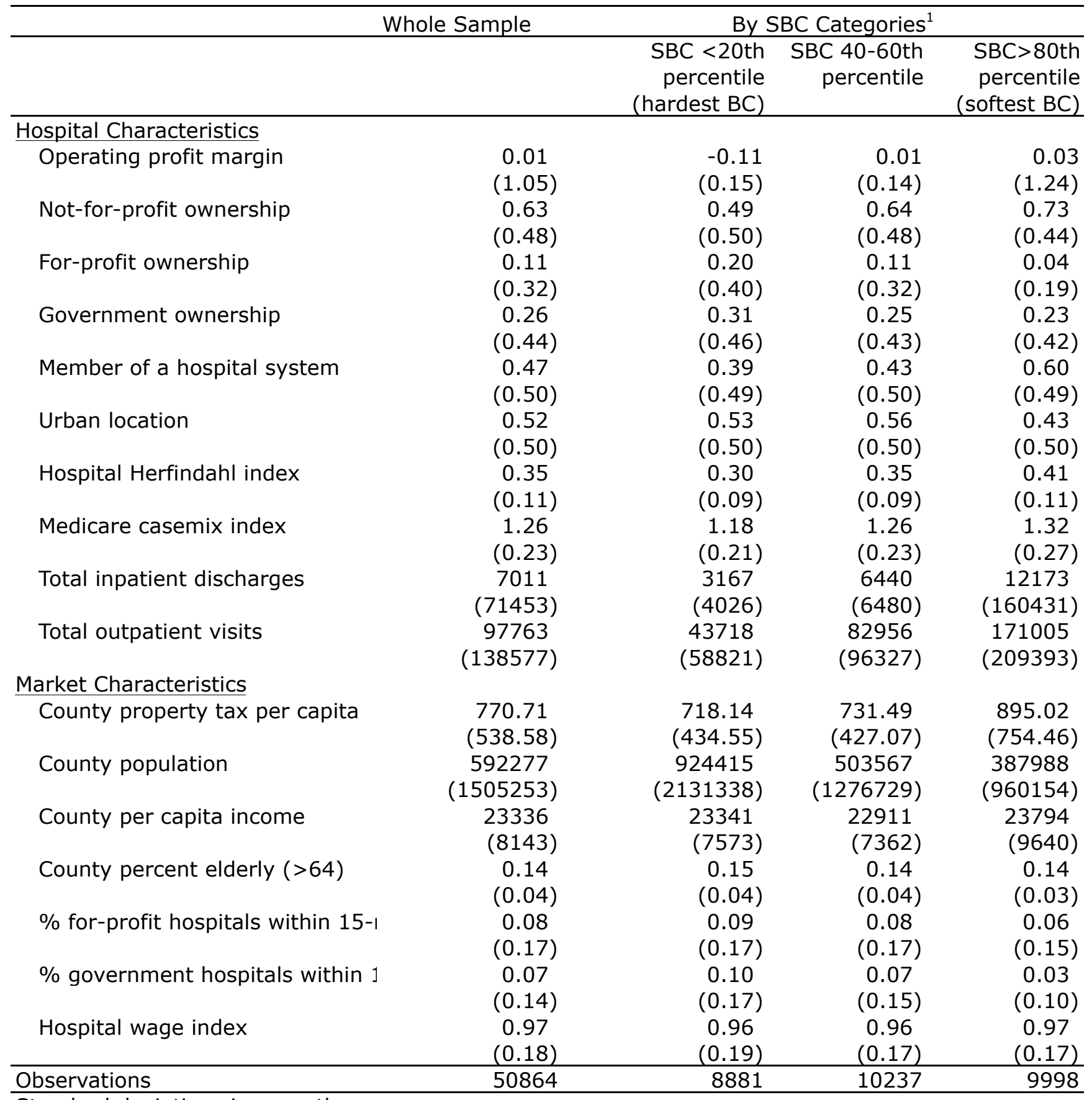

Standard deviations in parentheses

${ }^{1}$ The other 2 categories (20-40th percentile, 60-80th percentile) are available upon request. 
Table 3. Effect of Soft Budget Constraint on Survival of Hospital Safety Net Services

\begin{tabular}{|c|c|c|c|c|}
\hline \multirow[b]{2}{*}{$\begin{array}{l}\text { Hazard ratio } \\
\text { (boostrapped SE) }\end{array}$} & \multicolumn{4}{|c|}{ Service Survival (1990-2005) } \\
\hline & $\begin{array}{l}\text { Inpatient } \\
\text { substance } \\
\text { abuse }\end{array}$ & $\begin{array}{l}\text { Outpatient } \\
\text { substance } \\
\text { abuse }\end{array}$ & $\begin{array}{l}\text { HIV/AIDS } \\
\text { Services }\end{array}$ & $\begin{array}{l}\text { Emergency } \\
\text { Department }\end{array}$ \\
\hline \multicolumn{5}{|c|}{ By Soft Budget Constraints Categories } \\
\hline $\begin{array}{l}\mathrm{SBC}<20 \text { th percentile } \\
\text { (reference group) }\end{array}$ & 1.00 & 1.00 & 1.00 & 1.00 \\
\hline SBC 20-40th percentile & $\begin{array}{l}0.93 \\
(0.20)\end{array}$ & $\begin{array}{l}0.88 \\
(0.18)\end{array}$ & $\begin{array}{l}0.88 \\
(0.15)\end{array}$ & $\begin{array}{l}0.72 \\
(0.15)\end{array}$ \\
\hline SBC 40-60th percentile & $\begin{array}{l}0.89 \\
(0.19)\end{array}$ & $\begin{array}{l}0.82 \\
(0.15)\end{array}$ & $\begin{array}{l}0.70 * \\
(0.12)\end{array}$ & $\begin{array}{l}0.73 \\
(0.17)\end{array}$ \\
\hline SBC 60-80th percentile & $\begin{array}{l}0.65+ \\
(0.15)\end{array}$ & $\begin{array}{l}0.69+ \\
(0.15)\end{array}$ & $\begin{array}{l}0.76 \\
(0.14)\end{array}$ & $\begin{array}{l}0.49 * \\
(0.14)\end{array}$ \\
\hline SBC $>$ 80th percentile & $\begin{array}{l}0.57^{*} \\
(0.15)\end{array}$ & $\begin{array}{l}0.52 * * \\
(0.12)\end{array}$ & $\begin{array}{l}0.57^{*} \\
(0.13)\end{array}$ & $\begin{array}{l}0.52 * \\
(0.17)\end{array}$ \\
\hline \multicolumn{5}{|l|}{ By Profit Margin Categories } \\
\hline $\begin{array}{l}\text { Profit margin <20th percentile } \\
\text { (reference group) }\end{array}$ & 1.00 & 1.00 & 1.00 & 1.00 \\
\hline Profit margin $20-40$ th percentile & $\begin{array}{l}1.52 * \\
(0.26)\end{array}$ & $\begin{array}{l}0.97 \\
(0.15)\end{array}$ & $\begin{array}{l}1.11 \\
(0.17)\end{array}$ & $\begin{array}{l}0.83 \\
(0.15)\end{array}$ \\
\hline Profit margin $40-60$ th percentile & $\begin{array}{l}1.30 \\
(0.24)\end{array}$ & $\begin{array}{l}1.11 \\
(0.17)\end{array}$ & $\begin{array}{l}1.21 \\
(0.18)\end{array}$ & $\begin{array}{l}0.72+ \\
(0.14)\end{array}$ \\
\hline Profit margin $60-80$ th percentile & $\begin{array}{l}1.49 * \\
(0.27)\end{array}$ & $\begin{array}{l}1.06 \\
(0.17)\end{array}$ & $\begin{array}{l}1.28 \\
(0.20)\end{array}$ & $\begin{array}{l}0.56 * * \\
(0.13)\end{array}$ \\
\hline Profit margin $>$ 80th percentile & $\begin{array}{l}1.53 * \\
(0.28)\end{array}$ & $\begin{array}{l}1.52 * \\
(0.25)\end{array}$ & $\begin{array}{l}1.43^{*} \\
(0.22)\end{array}$ & $\begin{array}{l}0.77 \\
(0.16)\end{array}$ \\
\hline Observations & 5863 & 9327 & 11639 & 43981 \\
\hline
\end{tabular}

+ significant at $10 \%$; $*$ significant at $5 \%$; ** significant at $1 \%$

Year dummies and Census region dummies are included

Hospital sample includes all general, acute, short-stay hospitals that are in continuous operation between 1990 and 2000

For SBC estimates, standard errors based on 1000 Bootstrap samples 
Table 4. Effect of Soft Budget Constraint on AMI Mortality Rates

\begin{tabular}{|c|c|c|c|}
\hline \multirow[b]{2}{*}{ Coefficients (bootstrapped SE) } & \multicolumn{3}{|c|}{ AMI Mortality (1994-2004) } \\
\hline & 30-day & 90-day & 1-year \\
\hline \multicolumn{4}{|c|}{ By Soft Budget Constraints Categories } \\
\hline $\begin{array}{l}\mathrm{SBC}<20 \text { th percentile } \\
\text { (reference group) }\end{array}$ & -- & -- & -- \\
\hline SBC 20-40th percentile & $\begin{array}{l}-0.005^{*} \\
(0.002)\end{array}$ & $\begin{array}{l}-0.006 * * \\
(0.002)\end{array}$ & $\begin{array}{l}-0.007 * * \\
(0.002)\end{array}$ \\
\hline SBC 40-60th percentile & $\begin{array}{l}-0.009 * * \\
(0.002)\end{array}$ & $\begin{array}{l}-0.010 * * \\
(0.002)\end{array}$ & $\begin{array}{l}-0.010 * * \\
(0.003)\end{array}$ \\
\hline SBC 60-80th percentile & $\begin{array}{l}-0.010 * * \\
(0.002)\end{array}$ & $\begin{array}{l}-0.011^{* *} \\
(0.003)\end{array}$ & $\begin{array}{l}-0.011 * * \\
(0.003)\end{array}$ \\
\hline SBC $>$ 80th percentile & $\begin{array}{l}-0.010 * * \\
(0.003)\end{array}$ & $\begin{array}{l}-0.012^{* *} \\
(0.003)\end{array}$ & $\begin{array}{l}-0.011^{* *} \\
(0.003)\end{array}$ \\
\hline \multicolumn{4}{|l|}{ By Profit Margin Categories } \\
\hline $\begin{array}{l}\text { Profit margin <20th percentile } \\
\text { (reference group) }\end{array}$ & -- & -- & -- \\
\hline Profit margin $20-40$ th percentile & $\begin{array}{l}-0.003 * * \\
(0.001)\end{array}$ & $\begin{array}{l}-0.003 * * \\
(0.001)\end{array}$ & $\begin{array}{l}-0.005 * * \\
(0.001)\end{array}$ \\
\hline Profit margin 40-60th percentile & $\begin{array}{l}-0.007 * * \\
(0.001)\end{array}$ & $\begin{array}{l}-0.008 * * \\
(0.001)\end{array}$ & $\begin{array}{l}-0.010 * * \\
(0.001)\end{array}$ \\
\hline Profit margin $60-80$ th percentile & $\begin{array}{l}-0.005^{* *} \\
(0.001)\end{array}$ & $\begin{array}{l}-0.007 * * \\
(0.001)\end{array}$ & $\begin{array}{l}-0.010 * * \\
(0.001)\end{array}$ \\
\hline Profit margin $>80$ th percentile & $\begin{array}{l}-0.007 * * \\
(0.001)\end{array}$ & $\begin{array}{l}-0.008^{* *} \\
(0.001)\end{array}$ & $\begin{array}{l}-0.011 * * \\
(0.001)\end{array}$ \\
\hline Observations & 20209 & 20209 & 20209 \\
\hline
\end{tabular}

+ significant at $10 \%$; $*$ significant at $5 \%$; ** significant at $1 \%$

Year dummies and Census region dummies are included

Hospital sample includes all general, acute, short-stay hospitals that are in continuous operation between 1990 and 2000

For SBC estimates, standard errors based on 1000 Bootstrap samples 
Appendix A1. Estimating Probability of Hospital Closure To Capture Softness of Budget Constraints

Variables

Coefficients

Financial characteristics

Indicator for reporting negative net income in current year

$0.625^{* *}$

(0.095)

Indicator for reporting negative net income in previous year

$0.475 * *$

Operating margin in current year

(0.089)

$-0.408 * *$

Operating margin in previous year

$(0.152)$

$-0.205+$

$(0.112)$

Other hospital characteristics

For-profit hospital

0.168

Government hospital

$(0.117)$

$-0.088$

$(0.113)$

Teaching hospital

$-0.816^{*}$

$(0.382)$

Indicator for urban location

0.235

$(0.144)$

Indicator for hospital system membership

$-0.280 * *$

(0.087)

Log(hospital herfindahl index)

$-0.159$

$(0.144)$

Log (hospital case mix index)

$0.776 *$

Log(total inpatient discharges)

(0.306)

$-0.189 * *$

(0.048)

Log(total outpatient visits)

$-0.194 * *$

(0.049)

Log(hospital wage index)

$1.341 * *$

(0.459)

Market characteristics

Property tax per capita (county level)

$-0.0003+$

$(0.0002)$

Property tax per capita X for-profit ownership

0.0001

$(0.0002)$

Property tax per capita X government ownership

$-0.0003$

$\%$ elderly in the county

$(0.0002)$

0.993

(1.200)

Log(county population)

$0.126 * *$

$(0.046)$

Log(per capita income)

$-0.104$

$(0.282)$

$\%$ for-profit hospitals within 15 -mile radius

$-0.126$

$(0.294)$

$\%$ government hospitals within 15 -mile radius

$0.453+$

(0.247)

Constant

$-2.278 * *$

(0.178)

Observations

4820

Standard errors in parentheses

+ significant at $10 \%$; $*$ significant at $5 \%$; ** significant at $1 \%$ 
Appendix A2. Full Model Results on Effect of Soft Budget Constraint on Hazard Ratio of Service Exit (1990-2005)

\begin{tabular}{|c|c|c|c|c|}
\hline Hazard ratio (Bootstrap Standard Errors) & $\begin{array}{l}\text { Inpatient substance } \\
\text { abuse }\end{array}$ & $\begin{array}{l}\text { Outpatient } \\
\text { substance abuse }\end{array}$ & $\begin{array}{l}\text { HIV/AIDS } \\
\text { Services }\end{array}$ & $\begin{array}{l}\text { Emergency } \\
\text { Department }\end{array}$ \\
\hline $\begin{array}{l}\text { SBC }<20 \text { th percentile } \\
\text { (reference group) }\end{array}$ & -- & -- & -- & -- \\
\hline SBC 20-40th percentile & $\begin{array}{l}0.93 \\
(0.20)\end{array}$ & $\begin{array}{l}0.88 \\
(0.18)\end{array}$ & $\begin{array}{l}0.88 \\
(0.15)\end{array}$ & $\begin{array}{l}0.72 \\
(0.15)\end{array}$ \\
\hline SBC 40-60th percentile & $\begin{array}{l}0.89 \\
(0.19)\end{array}$ & $\begin{array}{l}0.82 \\
(0.15)\end{array}$ & $\begin{array}{l}0.70 * \\
(0.12)\end{array}$ & $\begin{array}{l}0.73 \\
(0.17)\end{array}$ \\
\hline SBC 60-80th percentile & $\begin{array}{l}0.65+ \\
(0.15)\end{array}$ & $\begin{array}{l}0.69+ \\
(0.15)\end{array}$ & $\begin{array}{l}0.76 \\
(0.14)\end{array}$ & $\begin{array}{l}0.49 * \\
(0.14)\end{array}$ \\
\hline SBC $>$ 80th percentile & $\begin{array}{l}0.57^{*} \\
(0.15)\end{array}$ & $\begin{array}{l}0.52 * * \\
(0.12)\end{array}$ & $\begin{array}{l}0.57^{*} \\
(0.13)\end{array}$ & $\begin{array}{l}0.52 * \\
(0.17)\end{array}$ \\
\hline For-profit hospital & $\begin{array}{l}1.20 \\
(0.23)\end{array}$ & $\begin{array}{l}1.36+ \\
(0.25)\end{array}$ & $\begin{array}{l}1.29 \\
(0.23)\end{array}$ & $\begin{array}{l}2.18^{* *} \\
(0.45)\end{array}$ \\
\hline Government hospital & $\begin{array}{l}1.34+ \\
(0.23)\end{array}$ & $\begin{array}{l}1.03 \\
(0.18)\end{array}$ & $\begin{array}{l}1.11 \\
(0.14)\end{array}$ & $\begin{array}{l}1.20 \\
(0.23)\end{array}$ \\
\hline Indicator for hospital system membership & $\begin{array}{l}1.20 \\
(0.13)\end{array}$ & $\begin{array}{l}1.06 \\
(0.12)\end{array}$ & $\begin{array}{l}1.27 * \\
(0.14)\end{array}$ & $\begin{array}{l}1.35+ \\
(0.21)\end{array}$ \\
\hline Indicator for urban location & $\begin{array}{l}0.78 \\
(0.14)\end{array}$ & $\begin{array}{l}0.74+ \\
(0.12)\end{array}$ & $\begin{array}{l}0.98 \\
(0.17)\end{array}$ & $\begin{array}{l}1.26 \\
(0.29)\end{array}$ \\
\hline Log(hospital herfindahl index) & $\begin{array}{l}0.77 \\
(0.17)\end{array}$ & $\begin{array}{l}0.84 \\
(0.17)\end{array}$ & $\begin{array}{l}1.26 \\
(0.25)\end{array}$ & $\begin{array}{l}0.62+ \\
(0.16)\end{array}$ \\
\hline Log (hospital case mix index) & $\begin{array}{l}1.02 \\
(0.44)\end{array}$ & $\begin{array}{l}0.78 \\
(0.35)\end{array}$ & $\begin{array}{l}0.14^{* *} \\
(0.06)\end{array}$ & $\begin{array}{l}0.16^{* *} \\
(0.09)\end{array}$ \\
\hline Log(total inpatient discharges) & $\begin{array}{l}0.93 \\
(0.10)\end{array}$ & $\begin{array}{l}0.98 \\
(0.10)\end{array}$ & $\begin{array}{l}0.99 \\
(0.09)\end{array}$ & $\begin{array}{l}0.81^{*} \\
(0.09)\end{array}$ \\
\hline Log(total outpatient visits) & $\begin{array}{l}1.15 \\
(0.11)\end{array}$ & $\begin{array}{l}0.89 \\
(0.07)\end{array}$ & $\begin{array}{l}0.87+ \\
(0.06)\end{array}$ & $\begin{array}{l}0.93 \\
(0.08)\end{array}$ \\
\hline Log(hospital wage index) & $\begin{array}{l}0.44 \\
(0.23)\end{array}$ & $\begin{array}{l}0.19 * * \\
(0.09)\end{array}$ & $\begin{array}{l}0.26 * * \\
(0.13)\end{array}$ & $\begin{array}{l}2.00 \\
(1.66)\end{array}$ \\
\hline Log(county population) & $\begin{array}{l}0.88+ \\
(0.07)\end{array}$ & $\begin{array}{l}0.97 \\
(0.07)\end{array}$ & $\begin{array}{l}1.00 \\
(0.06)\end{array}$ & $\begin{array}{l}0.99 \\
(0.08)\end{array}$ \\
\hline Log(per capita income) & $\begin{array}{l}2.55^{* *} \\
(0.64)\end{array}$ & $\begin{array}{l}2.41 * * \\
(0.63)\end{array}$ & $\begin{array}{l}2.98^{* *} \\
(0.75)\end{array}$ & $\begin{array}{l}2.08+ \\
(0.77)\end{array}$ \\
\hline$\%$ for-profit hospitals within 15 -mile radius & $\begin{array}{l}0.96 \\
(0.32)\end{array}$ & $\begin{array}{l}1.64 \\
(0.56)\end{array}$ & $\begin{array}{l}1.40 \\
(0.46)\end{array}$ & $\begin{array}{l}2.23+ \\
(1.00)\end{array}$ \\
\hline$\%$ government hospitals within 15 -mile radius & $\begin{array}{l}1.14 \\
(0.48)\end{array}$ & $\begin{array}{l}0.90 \\
(0.40)\end{array}$ & $\begin{array}{l}1.08 \\
(0.37)\end{array}$ & $\begin{array}{l}1.66 \\
(0.73)\end{array}$ \\
\hline Observations & 5863 & 9327 & 11639 & 43981 \\
\hline
\end{tabular}

+ significant at $10 \% ; *$ significant at $5 \% ; * *$ significant at $1 \%$

Year dummies and Census region dummies are included

Hospital sample includes all general, acute, short-stay hospitals that are in continuous operation between 1990 and 2000

Standard errors based on 1000 Bootstrap samples 


\section{Appendix A3. Full Model Results on Effect of Soft Budget Constraint on AMI Mortality Rates (1994-2004)}

\begin{tabular}{|c|c|c|c|}
\hline Hazard ratio (Bootstrap Standard Errors) & 30-day mortality & 90-day mortality & 1-year mortality \\
\hline $\begin{array}{l}\text { SBC }<20 \text { th percentile } \\
\text { (reference group) }\end{array}$ & 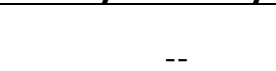 & 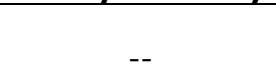 & 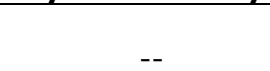 \\
\hline SBC 20-40th percentile & $\begin{array}{l}-0.005^{*} \\
(0.002)\end{array}$ & $\begin{array}{l}-0.006 * * \\
(0.002)\end{array}$ & $\begin{array}{l}-0.007 * * \\
(0.002)\end{array}$ \\
\hline SBC 40-60th percentile & $\begin{array}{l}-0.009 * * \\
(0.002)\end{array}$ & $\begin{array}{l}-0.010 * * \\
(0.002)\end{array}$ & $\begin{array}{l}-0.010 * * \\
(0.003)\end{array}$ \\
\hline SBC 60-80th percentile & $\begin{array}{l}-0.010^{* *} \\
(0.002)\end{array}$ & $\begin{array}{l}-0.011 * * \\
(0.003)\end{array}$ & $\begin{array}{l}-0.011^{* *} \\
(0.003)\end{array}$ \\
\hline SBC $>$ 80th percentile & $\begin{array}{l}-0.010 * * \\
(0.003)\end{array}$ & $\begin{array}{l}-0.012 * * \\
(0.003)\end{array}$ & $\begin{array}{l}-0.011^{* *} \\
(0.003)\end{array}$ \\
\hline For-profit hospital & $\begin{array}{l}0.011^{* *} \\
(0.002)\end{array}$ & $\begin{array}{l}0.011 * * \\
(0.003)\end{array}$ & $\begin{array}{l}0.009 * * \\
(0.003)\end{array}$ \\
\hline Government hospital & $\begin{array}{l}0.008 * * \\
(0.002)\end{array}$ & $\begin{array}{l}0.010 * * \\
(0.003)\end{array}$ & $\begin{array}{l}0.013 * * \\
(0.003)\end{array}$ \\
\hline Indicator for hospital system membership & $\begin{array}{l}0.003^{*} \\
(0.001)\end{array}$ & $\begin{array}{l}0.004 * * \\
(0.001)\end{array}$ & $\begin{array}{l}0.004 * * \\
(0.002)\end{array}$ \\
\hline Indicator for urban location & $\begin{array}{l}0.008^{* *} \\
(0.002)\end{array}$ & $\begin{array}{l}0.009 * * \\
(0.002)\end{array}$ & $\begin{array}{l}0.008^{* *} \\
(0.002)\end{array}$ \\
\hline Log(hospital herfindahl index) & $\begin{array}{l}-0.017 * * \\
(0.003)\end{array}$ & $\begin{array}{l}-0.026 * * \\
(0.003)\end{array}$ & $\begin{array}{l}-0.034 * * \\
(0.003)\end{array}$ \\
\hline Log (hospital case mix index) & $\begin{array}{l}-0.039 * * \\
(0.005)\end{array}$ & $\begin{array}{l}-0.056 * * \\
(0.006)\end{array}$ & $\begin{array}{l}-0.073 * * \\
(0.007)\end{array}$ \\
\hline Log(total inpatient discharges) & $\begin{array}{l}0.005 * * \\
(0.001)\end{array}$ & $\begin{array}{l}0.005^{* * *} \\
(0.002)\end{array}$ & $\begin{array}{l}0.004 * \\
(0.002)\end{array}$ \\
\hline Log(total outpatient visits) & $\begin{array}{l}0.002 * \\
(0.001)\end{array}$ & $\begin{array}{l}0.003 * * \\
(0.001)\end{array}$ & $\begin{array}{l}0.004 * * \\
(0.001)\end{array}$ \\
\hline Log(hospital wage index) & $\begin{array}{l}-0.012+ \\
(0.007)\end{array}$ & $\begin{array}{l}-0.010 \\
(0.007)\end{array}$ & $\begin{array}{l}0.002 \\
(0.008)\end{array}$ \\
\hline Log(county population) & $\begin{array}{l}0.004 * * \\
(0.001)\end{array}$ & $\begin{array}{l}0.005^{* *} * \\
(0.001)\end{array}$ & $\begin{array}{l}0.007 * * \\
(0.001)\end{array}$ \\
\hline Log(per capita income) & $\begin{array}{l}-0.024 * * \\
(0.004)\end{array}$ & $\begin{array}{l}-0.029 * * \\
(0.004)\end{array}$ & $\begin{array}{l}-0.035^{* *} \\
(0.005)\end{array}$ \\
\hline$\%$ for-profit hospitals within 15 -mile radius & $\begin{array}{l}-0.002 \\
(0.004)\end{array}$ & $\begin{array}{l}-0.004 \\
(0.004)\end{array}$ & $\begin{array}{l}-0.005 \\
(0.005)\end{array}$ \\
\hline$\%$ government hospitals within 15 -mile radius & $\begin{array}{l}-0.003 \\
(0.005)\end{array}$ & $\begin{array}{l}-0.008 \\
(0.005)\end{array}$ & $\begin{array}{l}-0.008 \\
(0.006)\end{array}$ \\
\hline Observations & 20209 & 20209 & 20209 \\
\hline
\end{tabular}

20209

20209

+ significant at $10 \% ; *$ significant at $5 \% ; * *$ significant at $1 \%$

Year dummies and Census region dummies are included

Hospital sample includes all general, acute, short-stay hospitals that are in continuous operation between 1990 and 2000

Standard errors based on 1000 Bootstrap samples 